\title{
A MILP methodology to optimize PV - Wind renewable energy systems
}

\author{
sizing
}

\author{
Regina Lamedica ${ }^{a}$, Ezio Santini ${ }^{a}$, Alessandro Ruvio ${ }^{a}$, Laura Palagi ${ }^{b}$, Irene Rossetta ${ }^{c}$ \\ aSAPIENZA University of Rome, Dept. of Astronautical, Electrical and Energy Engineering \\ bSAPIENZA University of Rome, Dept. of Computer, Control, and Management Engineering
}

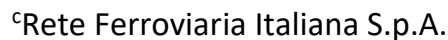




\section{Abstract}

The paper illustrates a methodology based on mixed integer linear programming (MILP) to calculate the optimal sizing of the hybrid wind-photovoltaic power plant of an industrial area. The methodology takes into account: i) load requirements; ii) physical and geometric constraints for the renewable plants installation; iii) operating and maintenance costs of both wind and PV power plants; iv) electric energy absorbed by the public network.

The power demand variation associated with the production cycles is taken into account by means of a stochastic simulation tool. To take into account both load and seasonality variability, and to adapt the methodology to the actual operating use of the power plant, the optimization has been performed separately for each month of the year. An integrated economic analysis is discussed. The methodology has been adopted to analyse an industrial plant in the Rome area used for trains depot and maintenance activity. The results, combining the needs of the plant activity with the renewable energy availability, allowed to identify optimal solutions and the relevant savings achievable.

Keywords: industrial power plant, mixed integer linear programming, optimization, renewable energy systems.

\section{Acronyms}

\begin{tabular}{|c|c|}
\hline$A_{b}$ & Area Occupied By A Wind Turbine \\
\hline$A_{\max }$ & Area For Wind Turbines \\
\hline$C_{e o l i c}, C_{p v}$ & Unit installation cost of a wind turbine and PV panel \\
\hline$C_{P V O \& M}$ & Unitary Operating And Maintenance Cost Of A Photovoltaic Panel \\
\hline$C_{\text {eolic } O \& M}$ & Unitary Operating And Maintenance Cost Of A Wind Turbine \\
\hline$C_{O \& M}$ & Total Operating and Maintenance Cost \\
\hline$C_{i, t o t}^{*}$ & Overall Installation Cost \\
\hline$C_{\text {network energy }}$ & Unitary Cost Of The Purchased Energy \\
\hline$F_{n}$ & Cash Flows At Period $\mathrm{N}$ \\
\hline HSWSO & Hybrid Solar-Wind System Optimization Sizing \\
\hline I (IRR) & Internal Rate Of Return \\
\hline$I_{m p}$ & Maximum Module Current \\
\hline Impp & Rated Current Of PV Panel \\
\hline$I_{s c}$ & Short Circuit Current of PV panel \\
\hline
\end{tabular}




\begin{tabular}{|c|c|}
\hline ki & Temperature Coefficient Related To Isc \\
\hline$k p$ & Temperature Coefficient At Module Power Max - Pmax \\
\hline$k v$ & Temperature Coefficient At Open Circuit - Voc \\
\hline$\gamma$ & Sun Elevation At Noon On The Horizon In Winter Solstice \\
\hline $\mathrm{L}$ & Longitudinal Dimension Of The Solar Module \\
\hline LCE & Levelised Cost Of Energy \\
\hline LLPs & Loss Of Load Probability \\
\hline LPSP & Loss Power Supply Probability \\
\hline MG & Micro Grid \\
\hline MPPT & Maximum Power Point Tracking System \\
\hline$n$ & Investment Lifespan \\
\hline$P_{d c n}$ & Rated DC Power \\
\hline PDFs & Probability Distribution Functions \\
\hline$P_{\max }$ & Maximum Module Power \\
\hline$P_{\text {eolic }}^{i}$ & Wind turbine power production, i-th Interval \\
\hline$P_{l o a d}^{i}$ & Power Demand, i-th Interval \\
\hline$P_{p v}^{i}$ & PV Power Production, i-th Interval \\
\hline Pmpp & Rated Power Of PV Panel \\
\hline$Q$ & The Ministerial Rate (Italian Laws) \\
\hline$R$ & Amortization Rate \\
\hline RES & Renewable Energy Source \\
\hline RSM & Response Surface Methodology \\
\hline$S_{\text {I }}$ & Area for Solar Panels Installation \\
\hline Umpp & Rated Voltage PV Panel \\
\hline$V_{m p}$ & Maximum Module Voltage \\
\hline$V_{o c}$ & Open Circuit Voltage \\
\hline$V_{r}$ & Residual Value At The End Of The Time Period \\
\hline$\beta$. & Solar Modules Tilt Angle \\
\hline$\theta$ & Solar Modules Orientation Angle \\
\hline
\end{tabular}




\section{Introduction}

Attention in energy saving and reduction of pollution caused by fossil fuels has been exponentially growing in recent years. Many studies focused on issues about rational management of the load in order to reduce energy absorption from the network [1-6]. Measurement campaigns and control actions are the keys to obtain this target, together with new solutions for real-time decision models in industrial load management [7]. The production of energy (even if partially) by means of Renewable Energy Source (RES) is an important feature for a modern Company. Beyond economic aspects, each industrial structure must be careful to environmental issues and to reduction of greenhouse gas emissions (Kyoto Protocol, 1997).

\subsection{The Italian scenario}

In the last two decades, the Italian electricity market has undergone continuous changes and developments. The privatization of the market (three steps in years 1996, 2003, 2009) has been followed by the introduction of European incentives for production from RESs. The fast development of these latter changed remarkably the structure itself of the electricity market. In Italy, between 2013 and 2016 RESs are rapidly grown. In 2016, electric energy production was almost 106 TWh including 23 TWh of solar (PV) and 17 TWh of wind energy [8].

\subsection{RES and Microgrids}

The Italian policy encouraged growing of RESs in order to support the use of clean energy in European green economy context. Nowadays, due to this policy, many old industrial facilities are introducing renewable sources, in a framework that will combine energy saving and energy production in the future development of Microgrids (MGs).

Large-scale RES production has to be integrated in power systems, in order to improve system operation, reliability, environmental sustainability and economic benefits [9].

Sizing of different RES and relevant coordination are two basic aspects for the correct operation of a MG. Economic and operational considerations state limits on the total amount of RESs that can be installed in electric power systems. Considerations about land use, power system reliability and electricity market design are among the many issues that impose constraints on the total deployment of renewables, with particular reference to non-programmable sources, mainly wind and solar energy $[10,11]$.

One of the most critical aspects of RESs is the energy production forecast, that depends on geographical and climatic parameters. To overcome this difficulty, many solutions have been proposed, such as modelling the uncertainty using fuzzy confidence intervals [12, 13], by using a proper probability distribution functions (PDFs) [14] or Autoregressive 
Moving Average Model (ARMA) model for PV power system [15], even by using Markov chains rules [16]. Often, Authors did not consider the probabilistic aspects, but they used simple output functions for the energy produced by the RESs [17] or they consider the production from PV always under MPPT (Maximum Power Point Tracking System) conditions [15]. Moreover, most of the studies use a sequence of steady-state situations with a time interval (typically one hour), depending on PV and wind models [18, 19].

\subsection{RES and optimization}

Once a forecasting model is available, the design of a MG can be modelled as an optimization problem and solved by suitable algorithms. In the last decades, applications of computer simulation for handling complex engineering systems emerged as a promising method. To deal with different types of optimization problems, a large number of optimization methods has been developed [20]. The use of a mathematical model gives an overall view of a complex system such an industrial MG is. Its use is justified whenever there are many possible alternative choices, when it is needed to analyze all of them, in order to determine the best one or at least an approximation to the "best" within a given tolerance. This approach is complementary to a ground-rule approach which relies on "common sense" rules, issued by someone with experience and mature judgment in the sector. This allows taking effective decisions and guarantees the optimal choices in competition with human experts.

Many studies have been performed to select the model that leads to a coherent and realistic solution for MG sizing, using different algorithms.

Some researches rely on existing optimization software, such as HOMER [21]; others develop their own optimization methodologies. Static and dynamic renewable performances are optimized in [22]; a multi-objective model to minimize both cost of energy and total greenhouse gas emissions of the system is shown in [23]. [24] deals with the optimal size of a hybrid PV-wind system at different loss of load probability (LLPs) based on available solar energy and wind speed; [18] describes a configuration which can achieve the desired loss power supply probability (LPSP) with minimum annualized cost of system. In [25], a comparison study on two design optimization models (single and multi-objective) for renewable energy system in low energy buildings and zero energy buildings has been conducted. In [26], Authors developed a model to optimize the sizes of different components of hybrid solar-wind power generation systems. The Hybrid Solar-Wind System Optimization Sizing (HSWSO) model consists of three modules: the model of the hybrid system, the model of Loss of Power Supply Probability (LPSP) and the model of the Levelised Cost of Energy (LCE). The LPSP technique has been also used in [27] where, for a given loss probability, different combinations of PV modules, wind turbines and battery banks have been determined. In [19] Authors used the response surface methodology (RSM) 
to determine the optimal size of an autonomous PV-wind integrated hybrid energy system. In most cases, genetic algorithms (GA) have been used to determine a solution of the proposed model [21].

Genetic Algorithms, Particle Swarm and more in general evolutionary methods, fit the class of heuristics which are widely used in engineering framework for their easy implementation. Heuristics methods are often used when a complete formulation is not explicitly available and/or when the dimension of the addressed problem is so large that an optimal solution may be not computable within the given computational time. However, such methods do not provide any kind of certification of the quality of the solution which in turn may strongly depend on the parameter settings.

Thus, when the mathematical model fits in the class of Linear Programming (LP) or Mixed Integer Linear Programming (MILP), these methods and, more in general, population-based methods are not the best suited for the solution of the corresponding problems.

In this direction, some authors propose model in the Linear Programming (LP) or Mixed Integer Linear Programming (MILP) class for power grids. See [28] for a review and e.g. $[29,30]$ for a LP model for the minimization of the components size and of total investment cost.

The use of MILP models allow to consider standard software for the solution of the problem. Indeed algorithms producing a certified optimal solution of LP, ILP and MILP are widely available and implemented in standard software, both commercial and open source. Interested readers can refer to the classical reference [31] and to the up-to-date [32] for ILP models and related algorithms.

Further it is necessary to take into account also the intrinsic stochastic behaviour of renewable energy, as in [24], and the uncertainty of the electric load demand.

In this paper, a model to determine the optimal size of Wind and PV apparatuses of a power plant is proposed; the model is in the class of Mixed Integer Linear Programming (MILP).

An integrated economic analysis of the investment through the Net Present Value (NPV) method is also performed, which allows to evaluate the convenience of the system over its lifetime.

The structure of the paper is as follow. Section 2 presents the main novelties of the proposed methodological approach, In Section 3 the MILP problem is defined. Sections 4 and 5 report the automatic procedure and the case study of an industrial area. Finally, Section 6 shows the results and section 7 presents the conclusions. 


\section{Novelty of methodological approach}

A methodology to determine in a systematic way the optimal size of PV-Wind renewable plants is defined.

Indeed, the use of a mathematical model embedded within a simulation framework taking into account specific constraints of the industrial area and load variability along the day in different year periods is proposed.

The approach aims to jontly determine both optimal sizes of the renewable plants and the amount of network energy from the grid that satisfies load requirements by minimizing the sum of the daily cost of the energy purchased and the daily operating and maintenance costs of RESs.

The main novelties of the proposed approach are that the electric load profile of a typical day of the year is taken into account and that the optimal sizing by accounting for the trend along a season daytime is determined. The analysis has been performed for each month of the year to provide optimal solutions for industrial plants characterised by power demand strongly variable in the year (e.g. sea villages that operate from May to October, high-mountain MGs that are populated three months in winter and two months in summer, oil platforms, archaeological parks), taking into account the RESs availability also. The methodology can be applied to industrial plant not qualified as prosumers and/or equipped with energy storage. The procedure is implemented in a user-friendly platform in MATLAB ${ }^{\circledR}$. An industrial plant located in Rome area was chosen to verify the SW applicability.

\section{Methodologic approach}

The models of the RESs plant take into account the non-programmable energy produced depending on multiple factors such as installation site, month, hour of the day and weather conditions. Weather conditions are supposed equal in different years (hypothesis justified by the study of Italian historical data). The considered data for the case study are imported from existing on-line database.

\subsection{Wind power plant model}

Typical shape of wind turbines power curve chosen by the Authors is reported in [33-36]

\subsection{PV power plant model}

To estimate the PV energy production, several factors such as solar radiation, exposition of modules and system efficiency have been considered, as reported in [18], [37 - 39].

To obtain realistic values of the energy produced according to the weather condition and to the season, parameters reported in $[4,40]$ were taken into account in the model. 


\subsection{Load Profile}

A load profile has to be defined through the power demand vs. time. The model requires a vector of power absorption and the values are considered to be constant in each time step.

The load profile can be obtained both through a measurement campaign, if the industrial site exists, and through the knowledge of power demand of similar plants if the system is in planning phase.

To take into account the load variability, starting from the values listed in the vector, the procedure performs a random extraction, creating new load profiles.

\subsection{Definition of the MILP model}

The numbers of wind turbines and PV panels represent the solution of Mixed Integer Linear Programming problem, identifying respectively the first and the second set of decision variables (unknowns). These values cannot be negative. The optimization model requires as input the main RESs characteristics, the local geographical restrictions and the load profile. An investment budget expected for the RESs installation is taken into account.

The full set of decision variables identified in the mathematical model are:

- $\quad \mathrm{x}_{1}$, the integer number of the wind turbines;

- $\quad \mathrm{x}_{2}$, the integer number of PV panels;

- $\quad \mathrm{X}_{3}, \ldots . ., \mathrm{X}_{\mathrm{N}+2}$, the energy purchased from the network at each interval $i=1, \ldots, \mathrm{N}$ in which the day is discretized.

The values of power load absorptions are stored in a vector and each value is specific of one of the $\mathrm{N}$ intervals in which the day is discretized. Being 1440 minutes of a day, the time interval discretization is $1440 / \mathrm{N}$ minutes.

Consequently, $\mathrm{N}$ time intervals are taken into account also for energy exchanges with the public network; the corresponding constraints to balance renewable production and load demand have to be defined. The number of variables depends on the number $\mathrm{N}$ intervals. If $\mathrm{N}$ is large, the model increases its accuracy. The value of $\mathrm{N}$ chosen by the Authors is 96 , corresponding to a discretization interval of 15 minutes, that is considered a good compromise between accuracy and computer times. This value was used in the case study (Section 6).

The definition of the MILP model requires the mathematical formalization of the objective function and of the restrictions as linear equalities or inequalities, which establish the relationships among the decision variables and the input data. 


\subsubsection{Objective function}

The objective function is defined by the overall cost, i.e. the sum of the operating and maintenance costs of the wind and PV power plants $[€ / \mathrm{kW}]$ and the purchase cost of network energy [€/kWh].

It can be assumed that these costs are proportional to the number of elements of the plants and to the quantity of the energy purchased by the network. Hence, the costs are represented by a linear function involving $x_{1}, x_{2}, x_{3}, \ldots . ., x_{N+2}$ variables. Since the total has to be minimized, the objective function is (3):

$$
\min _{x}\left(C_{\text {eolic O\&M }} * x_{1}+C_{P V \text { o\&M }} * x_{2}+\sum_{i=3}^{N+2} C_{\text {network energy }} * x_{i}\right)
$$

Where:

$C_{\text {eolic } O \& M}$ is the unit operating and maintenance cost of a wind turbine;

$C_{P V O \& M}$ is the unit operating and maintenance cost of a photovoltaic panel;

$C_{\text {network energy }}$ is the unit cost of the purchased energy that is assumed to be independent from the time interval.

\subsubsection{Constraints}

The decision variables, together with data, must satisfy some technological, economic and geometrical constraints. Mathematically, these constraints are expressed by linear equalities and inequalities involving the variables.

- Energy absorption

With the hypothesis that the energy can only be purchased from the public network, the energy value must be not negative. The constraint is in (4):

$$
x_{i} \geq 0 \quad i=1, \ldots, N+2
$$

\section{- Balance between renewable production and load demand}

In the $i$-th time interval, the balance between renewable production and load demand is expressed by equations (5).

$$
\left(P_{\text {eolic }}^{i} * x_{1}+P_{p v}^{i} * x_{2}\right) * \frac{\mathrm{m}}{\mathrm{N}}+x_{i+2}=P_{\text {load }}^{i} * \frac{\mathrm{m}}{\mathrm{N}} \quad(i=1, \ldots, N)
$$

Where:

$\mathrm{m}$ is the number of minutes in a day (1440);

$P_{\text {eolic }}^{i}, P_{p v}^{i}$ and $P_{\text {load }}^{i}$ are respectively wind turbine power production, PV power production and load power demand in the $i$-th time interval. 


\section{- Economic constraints}

To take into account costs limitation of wind turbines and PV panels, constraints have been considered, assuming a maximum available budget not to be exceeded. Mathematically, the expression is a linear inequality involving only $x_{1}$ and $x_{2}$, which ensures that the initial installation cost of wind turbines and PV panels does not exceed the fixed budget (6):

$$
C_{\text {eolic }} * x_{1}+C_{p v} * x_{2} \leq \text { budget }
$$

Where:

$C_{e o l i c}$ is the is the unit installation cost of a wind turbine;

$C_{p v}$ is the is the unit installation cost of a PV panel.

\section{- Geometric constraints}

These constraints refer to some geometrical details. As far as wind energy production is concerned, a constraint arises due to the limited available ground area for the installation of the wind turbines (7):

$$
x_{1} * A_{b} \leq A_{\max }
$$

Where:

$A_{b}$ is the basic ground area occupied by a wind turbine;

$A_{\max }$ is the available area.

The second constraint concerns the available installation space for the PV power plant (8):

$$
x_{2} \leq \frac{\left(S_{l}-3\right)}{L} * N_{\text {rows of panels }}
$$

Where:

$S_{l}$ is the larger side of the available area for the installation of solar panels $[\mathrm{m}]$

$L$ is the longitudinal dimension of each panel in meters;

$N_{\text {rows of panels }}$ is the number of rows of installed panels.

In (8), $s_{l}$ is decreased of three meters in order to consider the maintenance corridors, a central one of 1 meter and other two corridors, both 1 meter and located along the larger side.

To avoid shading of the solar panels and, consequently, a significant reduction of their production of energy, the correct number of rows of panels $N_{\text {rows of panels }}$ was calculated through (9): 


$$
\left\{\begin{array}{l}
N_{\text {rows of panels }}=\frac{\left(s_{l}-3\right)}{D} \\
D=L \cos \beta\left(1+\frac{\tan \beta}{\tan \gamma}\right)
\end{array}\right.
$$

Where:

$s_{l}$ is the smaller side of the available area for the installation of solar panels.

Also the smaller side must be reduced of three meters to take into account the presence of corridors.

Equation (8) leads to expression (10):

$$
x_{2} \leq \frac{\left(S_{l}-3\right) *\left(s_{l}-3\right)}{L^{2} * \cos \beta\left(1+\frac{\tan \beta}{\tan \gamma}\right)}
$$

\subsubsection{The MILP model equations}

In the MILP model there are therefore $\mathrm{N}+2$ variables and $3 * \mathrm{~N}+3$ constraints. Equations $(11,12,13,14,15)$ summarize the model.

$$
\begin{gathered}
\min _{x}\left(C_{\text {eolic O\&M }} * x_{1}+C_{P V \text { o\&M }} * x_{2}+\sum_{i=3}^{N+2} C_{\text {network energy }} * x_{i}\right) \\
\left(P_{\text {eolic }}^{i} * x_{1}+P_{p v}^{i} * x_{2}\right) * \frac{\mathrm{m}}{\mathrm{N}}+x_{i+2}=P_{\text {load }}^{i} * \frac{\mathrm{m}}{\mathrm{N}} \quad i=1, \ldots, N \\
x_{1} * A_{b} \leq A_{\max } \\
x_{2} \leq \frac{\left(S_{l}-3\right) *\left(s_{l}-3\right)}{L^{2} * \cos \beta\left(1+\frac{\tan \beta}{\tan \gamma}\right)} \\
C_{\text {eolic }} * x_{1}+C_{p v} * x_{2} \leq \text { budget }
\end{gathered}
$$

The model considers $x_{1}, x_{2}$ as integers and enforces non-negative solution as in Eq. (16)

$$
x_{i} \geq 0 i=1, \ldots, N+2
$$

The optimal solution of the problem can be obtained by using standard exact algorithms for MILP [31]-[32], which are implemented in most commercial software. Exact methods algorithms for MILP are roughly speaking implicit enumeration methods of Branch-and-Bounds or Branch-and-Cut type. The convergence of such methods to an optimal solution of the MILP is fully understood as discussed in [31]-[32]. We remark that LP and MILP can be solved to global optimality, in the sense that no better value of the objective can be reached, by properly setting the parameters of the algorithm. They also provide a certification of the accuracy of the obtained solution.

In MATLAB ${ }^{\circledR}$ implementation, the routine of the Optimization Toolbox “intlinprog" has been used.

\subsection{Investment evaluation and economic analysis}

The investment evaluation was conducted by calculating the NPV (Net Present Value).

The effectiveness of the investment is evaluated by adding up the various expenses and incomes, reporting these quantities to the same reference time through the discounting mechanism as in Eq. (17). 


$$
N P V=F_{0}+\frac{F_{1}}{(1+i)}+\frac{F_{2}}{(1+i)^{2}}+\cdots+\frac{F_{n}}{(1+i)^{n}}
$$

Where:

$n$ is the life span of the investment;

$F_{n}$ represents the cash flows (to evaluate the profitability of industrial investment) at the $n$-th period; $i$ is the IRR, "Internal Rate of Return" and it is chosen iteratively in relation to the length of the investment and to its economic availability.

This method requires to define a-priori " $n$ " and " $i$ " and it leads to these considerations:

- $\quad$ NPV>0: the investment will give an economic profit;

- $\quad N P V=0$ : the investment transaction will return in $n$ years the capital and interests at $i$ rate;

- $\quad$ NPV <0: the investment is not convenient, since it will return an economic loss.

Therefore, the investment is convenient only if NPV> 0. Different investments can be compared with this technique, and the one with greater NPV is the natural choice.

The cash flows calculation needs the MILP solutions relating revenues and operational/ maintenance cost of RESs. From each simulation, the optimal sizing of the renewable plants is obtained $\left(x^{* \text {,month }}\right)$.

The optimisation analysis is performed, month by month, for a full year. The number of wind turbines and PV panels is selected choosing the maximum value obtained among the results. Hence, the parameter considered are (18):

$$
x_{1, \text { ref }}=\max _{\text {month }=1, ., 12} x_{1}^{*, \text { month }} \quad x_{2, \text { ref }}=\max _{\text {month }=1, . ., 12} x_{2}^{*, \text { month }}
$$

Where:

$x_{1, \text { ref }}$ is the wind generators number;

$x_{2, r e f}$ is the PV panels number.

The cash flows is expressed with the following relationship (19):

$$
F=(i-p)\left(\text { Revenues }-C_{O \& M}^{*}\right)+p * A-C_{i, t o t}^{*}
$$

Where:

$i$ is the interest rate;

$p$ is the coefficient used to take into account the taxes;

$A$ is the annual amortization 
$C_{O \& M}^{*}$ and $C_{i, t o t}^{*}$ are respectively the operating and maintenance cost and total installation cost, considering $x_{1, \text { ref }}$ and $x_{2, r e f}$ which have the following expressions (20) (21):

$$
\begin{aligned}
& C_{O \& M}^{*}=C_{\text {eolic O\&M }} * x_{1, \text { ref }}+C_{P V \text { o\&M }} * x_{2, \text { ref }} \\
& C_{\text {tot }}^{*}=C_{\text {eolic }} * x_{1, \text { ref }}+C_{p v} * x_{2, \text { ref }}
\end{aligned}
$$

Revenues coincide with the cost of the energy saved in a year; they are calculated as the difference between the energy produced by RESs and the energy absorbed by the load.

The annual amortization estimation was calculated through (22):

$$
A=r * C_{i, t o t}=q
$$

Where:

$r$ is the devaluation rate;

$C_{i, t o t}$ is overall installation cost of the wind turbines, PV panels and interface inverters.

The $A$ value coincides with the rate " $q$ " (the value is set equal to $9 \%$ ). In Italy, the parameter represents the amortization percentage of the cost of capital goods used for commercial activities, arts and professions, established by the Ministry of Finance by Ministerial Decree dated 31 December 1988 and amended by Ministerial Decree dated 28 March 1996, in force since 16 May 1996.

\section{Case study}

The Rome subway has three lines, for a total length of $53 \mathrm{~km}$. The oldest is the line " $\mathrm{B}$ ", about $19 \mathrm{~km}$ long, opened in 1955 (the extension from stations "Termini" to "Rebibbia", in 1990); the line has a junction "B1" opened in 2012) about $4 \mathrm{~km}$ long. Line" $\mathrm{A}$ ", opened in 1980, is about $18 \mathrm{~km}$ long. The line "C" is the newest; only the section between "Pantano" and "San Giovanni" stations is in operation since 2014. Each Rome subway line is equipped with large available areas where metro trains deposits are located and maintenance activities are carried out.

The power plant chosen for the application of the proposed MILP model is the large facility "Officina Magliana" in which maintenance activities on metro trains of the line " $\mathrm{B}$ " are performed.

In "Officina Magliana" activities of assembling and disassembling mechanical and electrical components of the rolling stock, including profiling and lathing of the rims with the lathe in the pit, are carried out [41].

"Officina Magliana” has a medium voltage supply with dedicated substation equipped with MV/LV (20kV - 0.4 kV) transformers. The complete industrial plant consists of ten buildings as shown in Figure 1. 


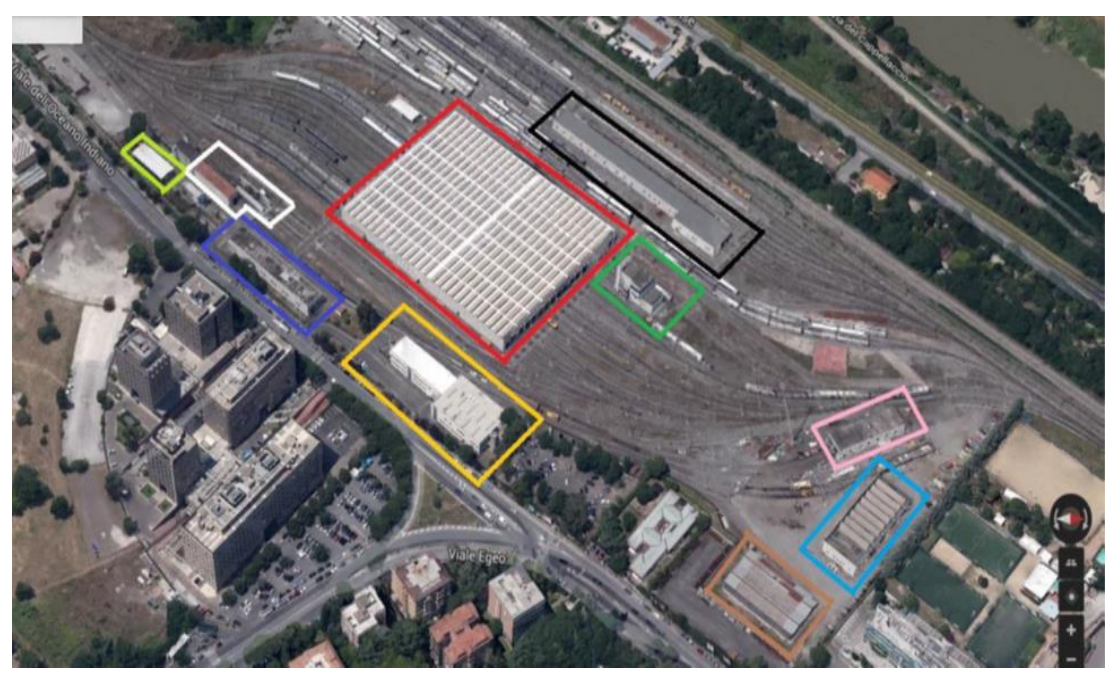

\begin{tabular}{|l|l|}
\hline 01 Maintenance by external executing company $\square$ & 06 Control Tower $\square$ \\
\hline 02 Building maintenance & 07 Roof wagons maintenance \\
\hline 03 Offices, Refectory, Bar, Changing Room $\square$ & 08 Thermal plant \\
\hline 04 Ecological Island $\square$ & 09 Electrical component storehouse \\
\hline 05 Warehouse & 10 Blowing and washing $\square$ \\
\hline
\end{tabular}

Figure 1. "Officina Magliana” deposit/maintenance and repair site.

The characteristic parameters of the "Officina Magliana” are listed in Table 1.

\begin{tabular}{|l|c|}
\hline Latitude $\left[{ }^{\circ}\right]$ & 41.82 \\
\hline Longitude $\left[{ }^{\circ}\right]$ & 12.44 \\
\hline Azimuth angle $\left[{ }^{\circ}\right]$ & 314 \\
\hline Height of the sun in winter solstice $[\gamma]$ & 24 \\
\hline Average wind speed $[\mathrm{m} / \mathrm{s}]$ & 3.81 \\
\hline Height from ground corresponding to the average wind speed value $[\mathrm{m}]$ & 12 \\
\hline Soil roughness coefficient & 3.5 \\
\hline Available area for wind power plant $\left[\mathrm{m}^{2}\right]$ & 15 \\
\hline Available area for PV power plant $\left[\mathrm{m}^{2}\right]$ & 8000 \\
\hline Tilt angle of solar panels $[\beta]$ & 16 \\
\hline Reflection coefficient & 0.13 \\
\hline Feeder Ampacity $[\mathrm{A}]$ & 370 \\
\hline
\end{tabular}

Table 1. "Officina Magliana” localization and characteristic data

The budget available by the transport Company for the investment is $300,000 €$; the operating and maintenance costs chosen are shown in Table 2 [42].

\begin{tabular}{|c|c|c|}
\hline & PV System & Wind System \\
\hline $\begin{array}{c}\text { Operating \& Maintenance } \\
\text { daily costs }[€ / \mathrm{kW}]\end{array}$ & $0.052^{*}$ & $0.095^{*}$ \\
\hline
\end{tabular}

Table 2. Objective function Coefficients.

\footnotetext{
* Data are referred to 2016
} 
The cost of the purchased energy depends on the agreement with the local electric distributor. Current electric energy cost was assumed equal to $0.18 € / \mathrm{kWh}$ (Italian energy price for energy delivered by MV network).

\subsection{Electric Load profiles}

The instrument used for the measurements campaign is the Chauvin Arnoux CA 8335 network analyser. The analyser can measure and log many quantities simultaneously, as well as transient waveforms and inrush currents. The measurement uncertainty is between \pm 0.3 and $\pm 2.5 \%$ (including the error for the current sensors), depending on the measured variables.

The thermal power plant, the building maintenance, the refectory building, bar and offices are the monitored electrical loads. For Lighting Tower, located in the area, a power consumption of $63 \mathrm{~kW}$, constant value from 6 p.m. to 6 a.m. has been measured. Figures $2 \mathrm{a}, 2 \mathrm{~b}$ and $2 \mathrm{c}$, show electrical demand of loads monitored in three working days.

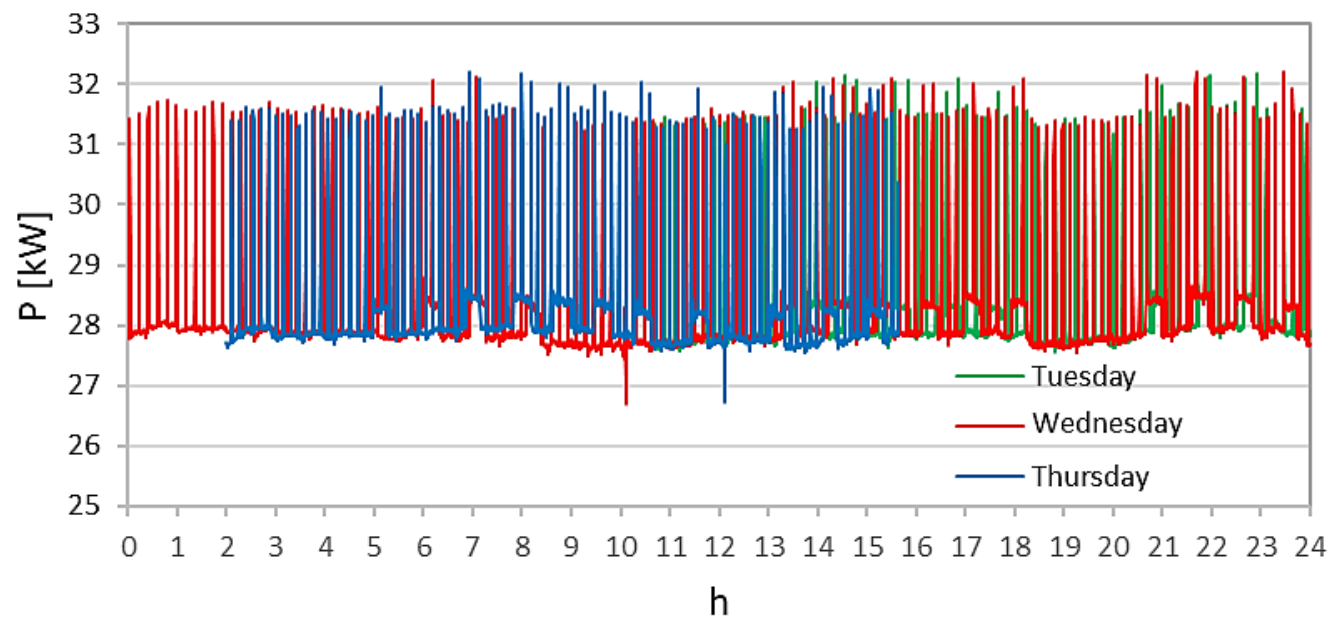

2. a

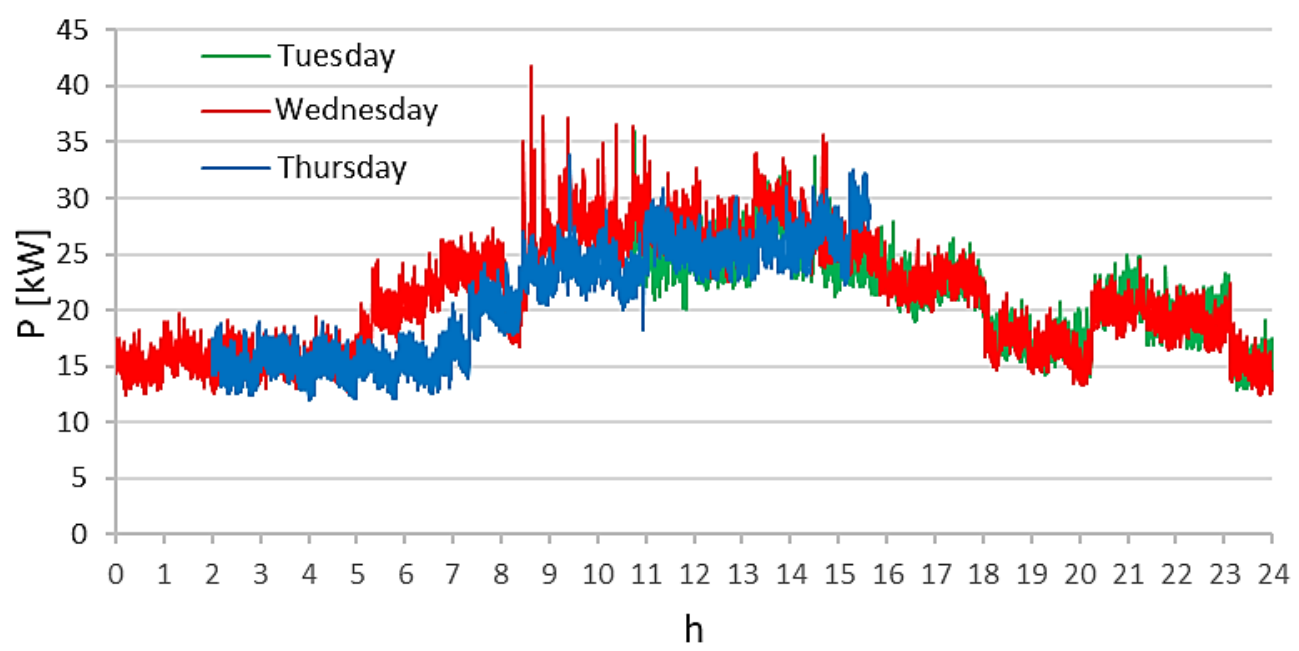




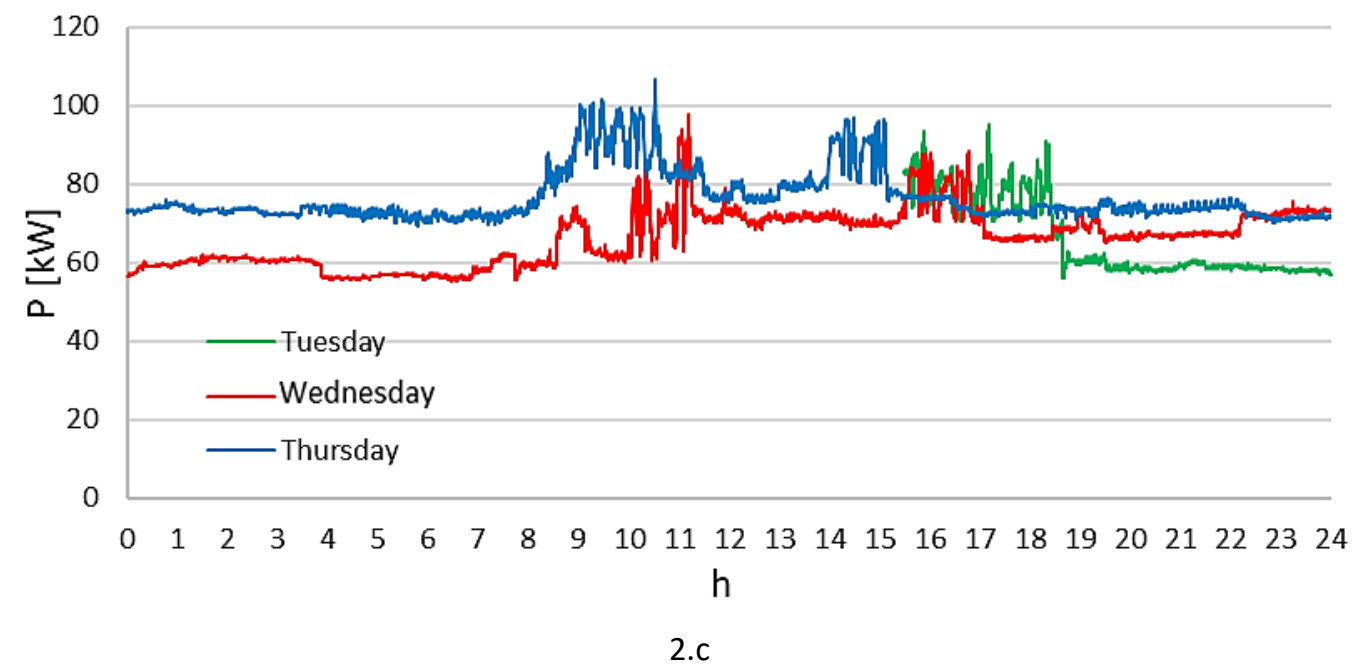

Figures 2a Thermal power plant power demand vs. time of the day; 3b Refectory, bar, offices power demand vs. time of the day; 3c Building Maintenance power demand vs. time of the day.

The power measurement on thermal power (Figure 2a) ranges between $27 \mathrm{~kW}$ and $32 \mathrm{~kW}$, due to the switch on/off operation of compressors installed in the area. The power consumption on Refectory, Bar and office (Figure $2 \mathrm{~b}$ ) ranges between $13 \mathrm{~kW}$ and $42 \mathrm{~kW}$. However, maximum consumption is recorded in each day from 7 a.m to 17 p.m due to working activities. The power request by the building of maintenance (Figure 2c) ranges between $55 \mathrm{~kW}$ and $105 \mathrm{~kW}$. In this case, the trend is different day by day. The maintenance activities are carried out 24 hours with a not scheduled programme.

Starting from these measurements, the proposed procedure creates randomly various day load profile as illustrated in Section 3.3.

\subsection{RES data}

Main characteristics of PV and Wind generators are listed in table 3.

\begin{tabular}{|l|l|c|}
\hline PV panel & \\
\hline & Rated power (Pmpp) [W] & 220 \\
\cline { 2 - 3 } & Rated voltage (Umpp) [V] & 27.91 \\
\cline { 2 - 3 } & Rated current (Impp) [A] & 7.88 \\
\cline { 2 - 3 } & Open circuit voltage (Uoc) [V] & 36.55 \\
\cline { 2 - 3 } & Short circuit current (Isc) [A] & 8.23 \\
\hline & Efficiency [\%] & 13.8 \\
\hline Power tolerance & $0 \%$ to $5 \%$ \\
\hline & Maximum voltage [V] & 1000 (EU) \\
\cline { 2 - 3 } & Operating temperature & $-40{ }^{\circ} \mathrm{C}$ to $+85{ }^{\circ} \mathrm{C}$ \\
\cline { 2 - 3 } & Temperature coefficient (Voc) & $-0.32 \% /{ }^{\circ} \mathrm{C}$ \\
\cline { 2 - 3 } & Temperature coefficient Pmax & $-0.35 \% /{ }^{\circ} \mathrm{C}$ \\
\cline { 2 - 3 } & Temperature coefficient (IsC) & $-0.04 \% /{ }^{\circ} \mathrm{C}$ \\
\cline { 2 - 3 } & NOTC & $51.5 \pm 3{ }^{\circ} \mathrm{C}$ \\
\cline { 2 - 3 } & Dimensions (LxLxA) [mm] & $1.639 \times 982 \times 35$ \\
\cline { 2 - 3 } & Price of each panel & $200 €$ \\
\hline
\end{tabular}




\begin{tabular}{|l|l|c|}
\hline Wind Generators & \multicolumn{2}{|c|}{} \\
\hline \multirow{2}{*}{} & Rated Power & $5 \mathrm{~kW}$ \\
\cline { 2 - 3 } & Tower height & $15 \mathrm{~m}$ \\
\cline { 2 - 3 } & Price & $1300 € / \mathrm{kW}$ \\
\cline { 2 - 3 }
\end{tabular}

Table 3. Electric and mechanics characteristic of a $220 \mathrm{~W}$ solar panel

\section{Results}

The proposed method has been implemented in Matlab ${ }^{\circledR}$ environment language. The software operates as a batch procedure. A graphical interface has been implemented to simplify data input. The outputs describe numerically the industrial area and the RES machines. The charts shown in the following represent the main output of the software.

\subsection{The monthly optimized results}

The optimization results of the 12 months are reported in Figures 3-6, each set of figures being relevant to the four seasons.

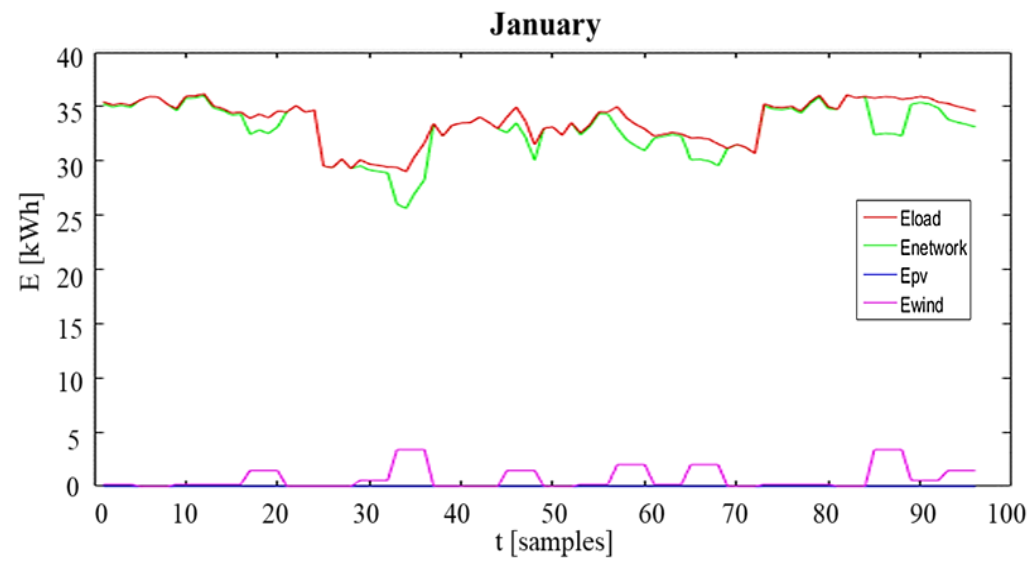

3.a

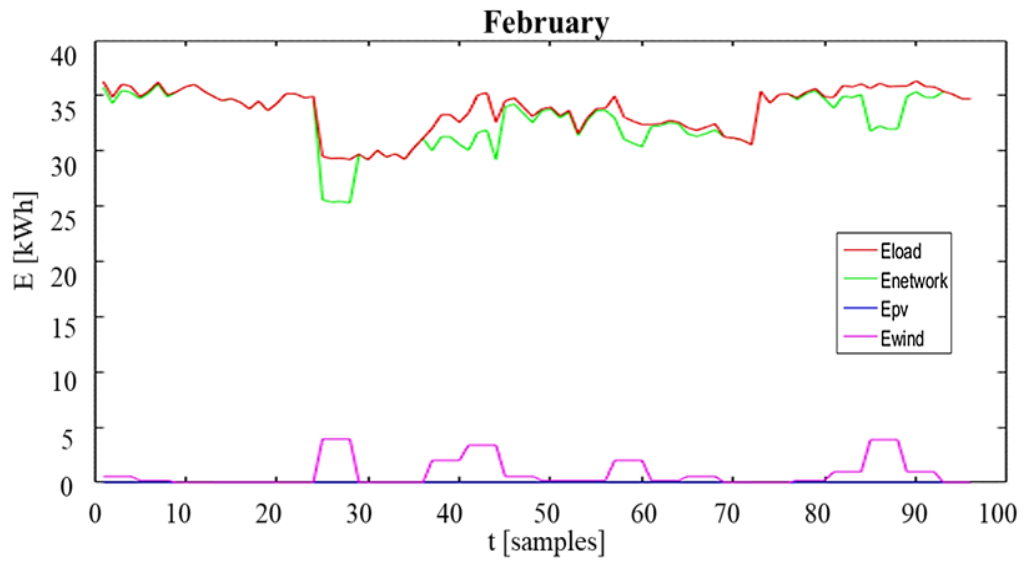

3.b 


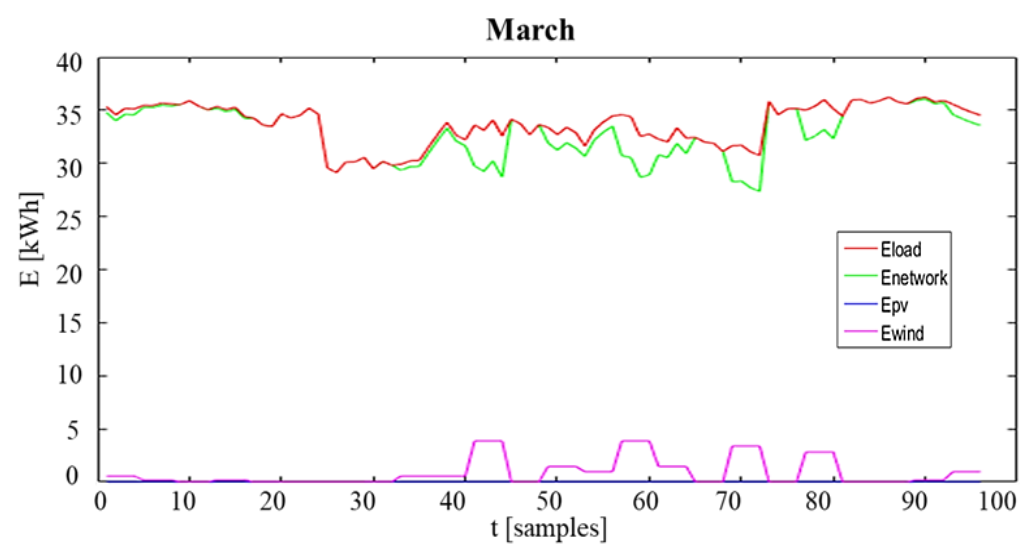

3.c

Figure 3. Energy profile of RES, network and load profile in a typical working day in Winter.

Figures $3 a, 3 b, 3 c$ highlight that in Winter season only wind turbines presence results from the optimisation. In fact, during these months (very similar one to the others), low PV production is expected; obviously, the procedure suggests to avoid installation of a PV plant. Three wind turbines are the solution provided by optimization.

Hence, only the wind plant provides the energy from RESs and the relevant revenues.

The wind generation provides up to $15 \%$ of the total energy requested by the loads and only for short periods during the day.

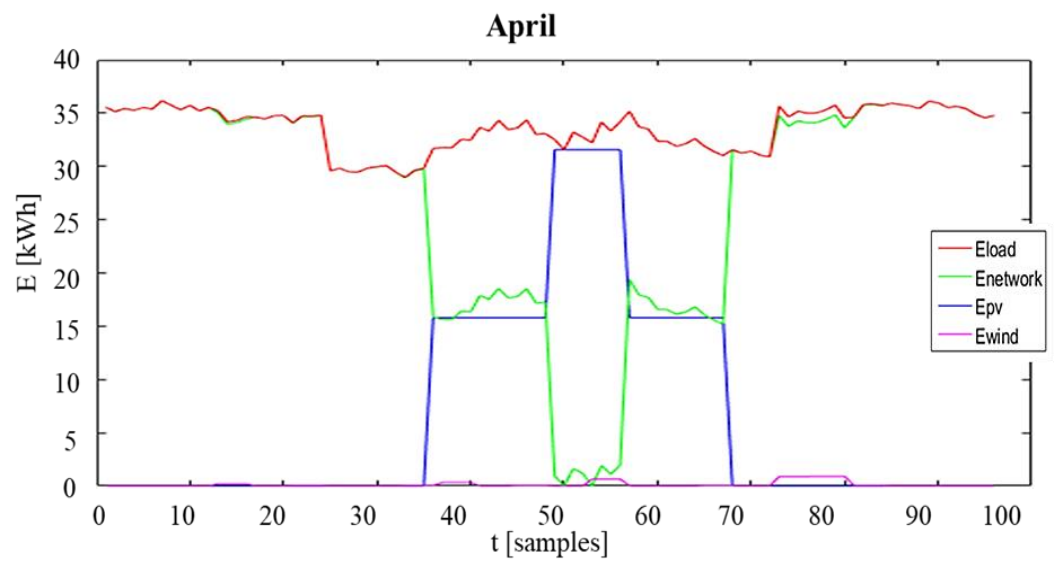

4.a 


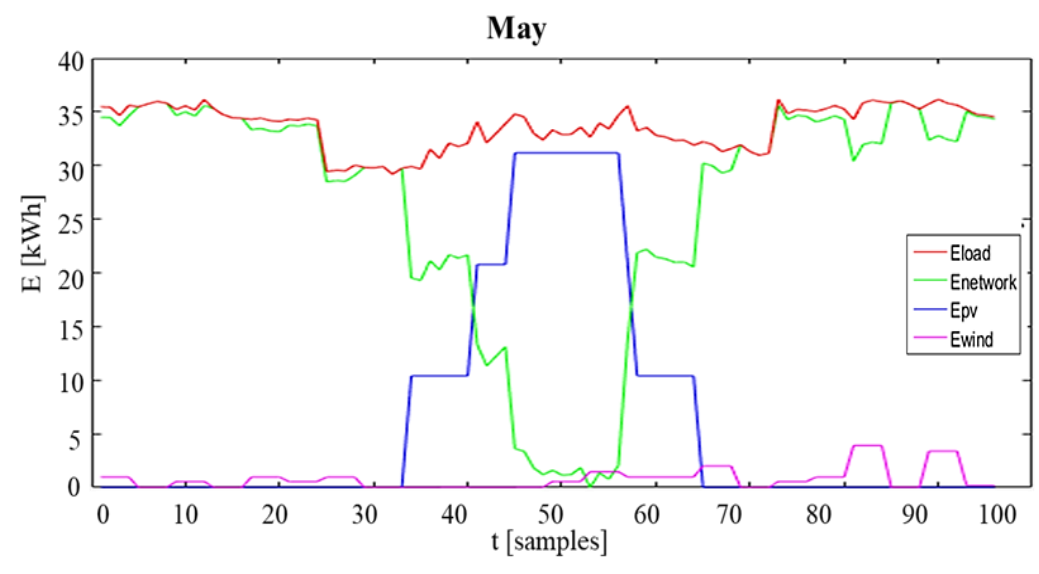

4.b

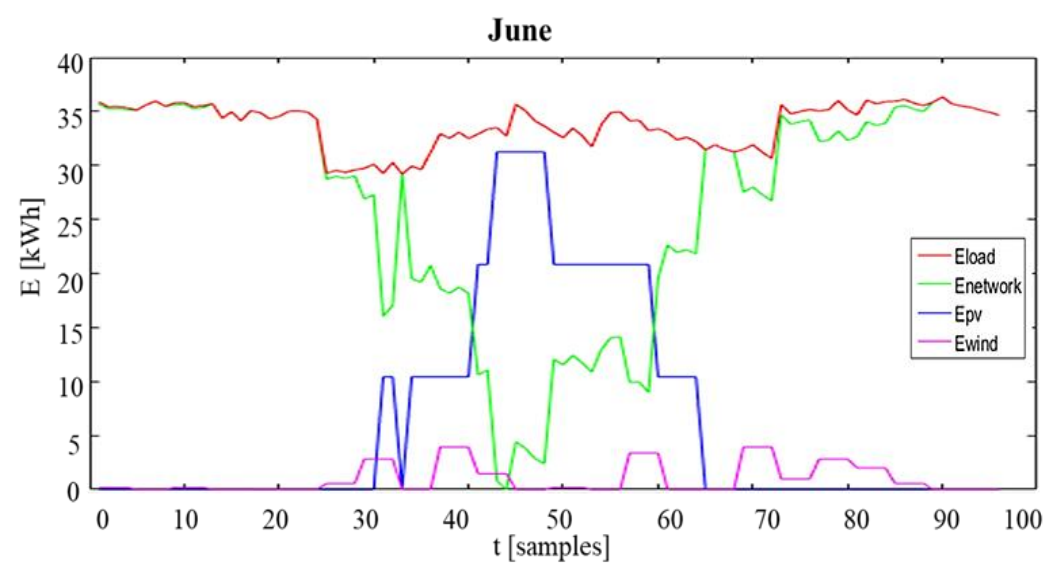

4.c

Figure 4. Energy profile of RES, network and load profile in a typical working days in Spring.

Figures. 4a, 4b, 4c show energy profiles in Spring season. The energy produced by the PV power plant increases respect to Winter. In April (Fig. 4.a) only one wind turbine and 631 solar panels are suggested. In this month, wind speed is not very high $(3 \mathrm{~m} / \mathrm{s})$ - it is less than in other months. The average energy in a day drawn from public network decreases from $33.58 \mathrm{kWh}$ to $26.92 \mathrm{kWh}$.

In May (Fig. 4.b), 3 wind turbines and 415 solar panels are obtained by optimization procedure. The significant number of panel is also due to the low wind power plant production, according to the unfavourable wind speed. The average network energy absorption decreases from $33.60 \mathrm{kWh}$ before optimization, to an average drawn energy after optimization of $26.30 \mathrm{kWh}$.

Both energy efficiency and the revenues are higher than in the winter months, due to the increase of the average wind speed $(3.79 \mathrm{~m} / \mathrm{s})$, present also during the night, when the photovoltaic system does not produce. 
In June, the number of suggested panels is slightly higher than in May. This is linked also to the further wind speed increase $(3.95 \mathrm{~m} / \mathrm{s})$. The network energy absorption decreases from $33.73 \mathrm{kWh}$ to $26.5 \mathrm{kWh}$.

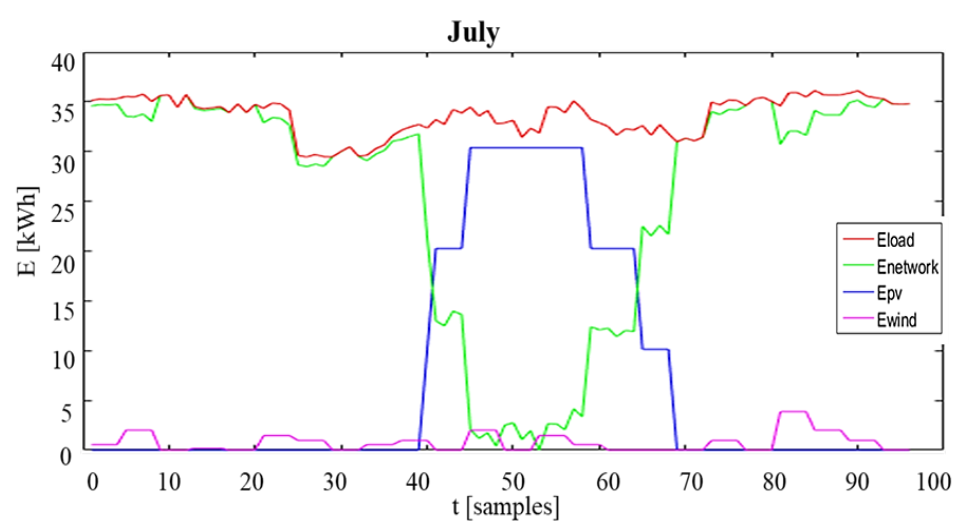

$5 . a$

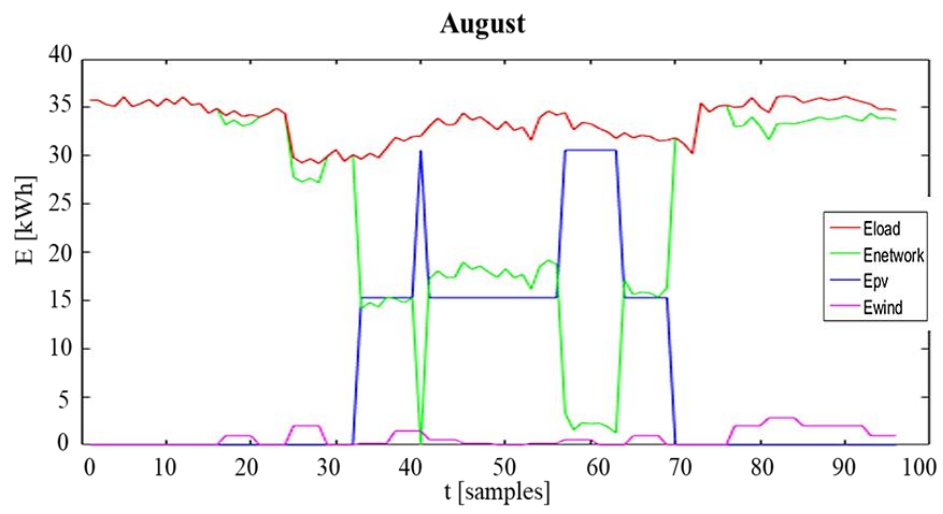

5.b

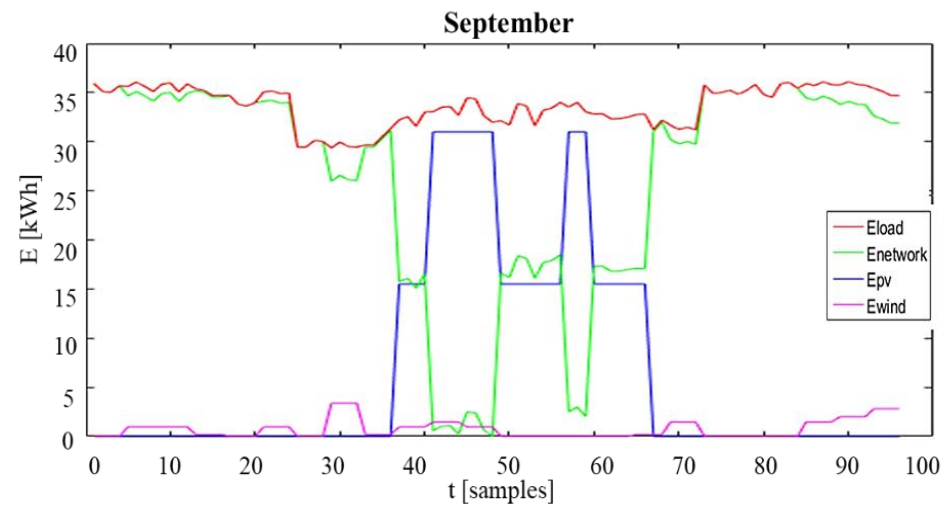

5.c

Fig. 5. Energy profile of RES, network and load profile in a typical working days in Summer.

Summer season results are similar to spring. The more favourable weather conditions in July (Figure 5a), involve a reduction of the solar panels (405, in May they are 415) and the network average energy absorption in a day decreases 
(25.8 kWh, in May: 26.3 kWh). In August (Fig. 5.b), the weather conditions are not the most favourable; therefore, the procedure selects a larger number of panels, 611 . The network average energy absorption in a day decreases from 33.63 kWh to $25.69 \mathrm{kWh}$. In September (figure 5.c), the number of panels is slightly higher than in August. The network average energy absorption in a day decreases from $33.64 \mathrm{kWh}$ to $25.26 \mathrm{kWh}$. Also in Autumn season, the optimization solution provides 3 turbines.

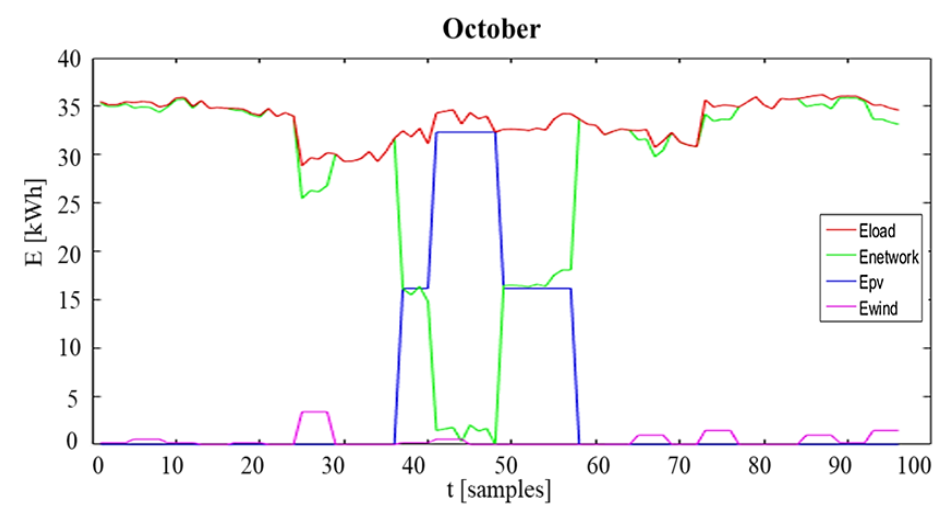

$6 . a$

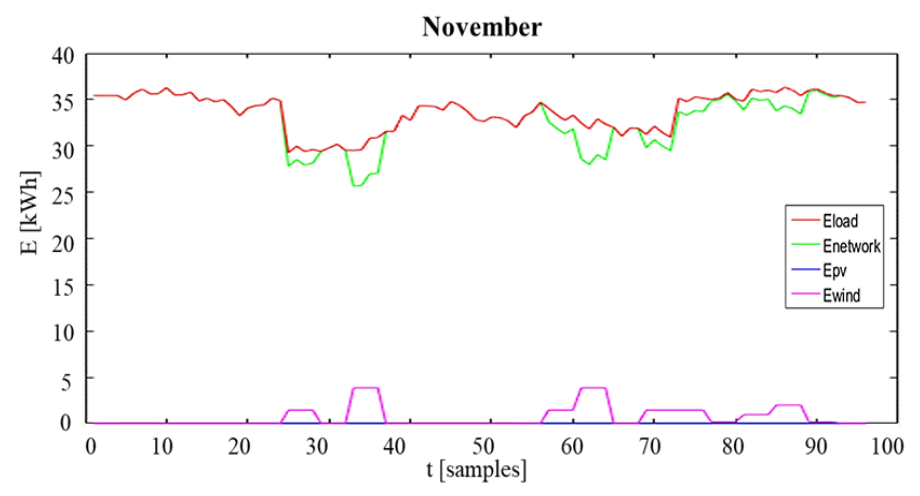

6.b

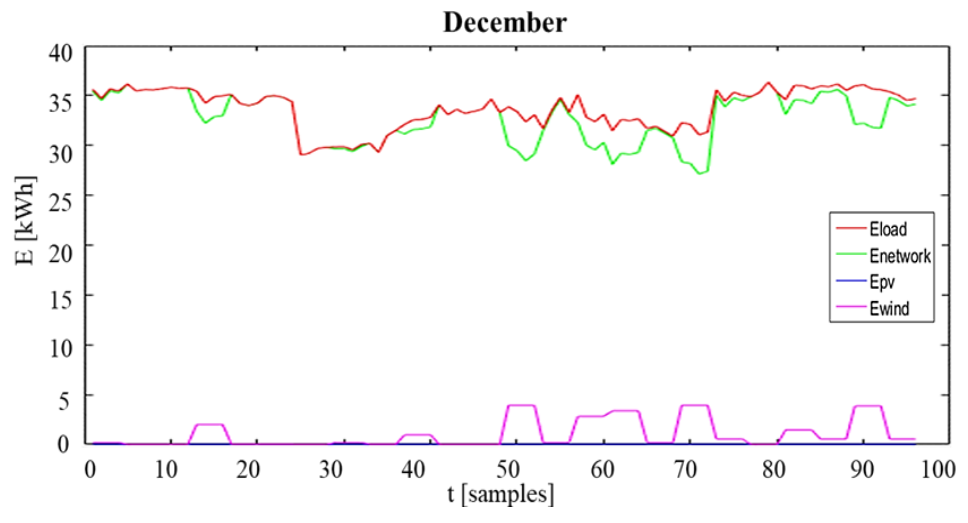

6.c

Fig. 6. Energy profile of RES, network and load profile in a typical working day in Autumn. 
In October (Fig. 6.a), the number of the PV panels is the highest in the year, due to the low energy production of the solar panels during cloudy day in autumn and to the low energy production of the wind power plant. The network average energy absorption in a day decreases from $33.62 \mathrm{kWh}$ to $28.3 \mathrm{kWh}$.

In November, as in the other Autumn months of Figs. 6, the procedure does not propose PV panels: their production is almost zero. The average wind speed recorded is $3.5 \mathrm{~m} / \mathrm{s}$. The network average energy absorption in a day decreases from $33.69 \mathrm{kWh}$ to $33 \mathrm{kWh}$.

In December, no PV panels are chosen. The average wind speed is $4.29 \mathrm{~m} / \mathrm{s}$, much higher than all the winter months.

The average energy absorption from the network in a day decreases from $33.69 \mathrm{kWh}$ to $32.6 \mathrm{kWh}$.

Table 4 reports the main results obtained for one month of each season: January for Winter, May for Spring, July for Summer and October for Autumn. The RESs costs are also reported.

\begin{tabular}{|c|c|c|c|c|}
\hline & January & May & July & October \\
\hline $\mathrm{N}^{\circ}$ of $5 \mathrm{~kW}$ wind turbines & 3 & 3 & 3 & 3 \\
\hline $\mathrm{N}^{\circ}$ of $220 \mathrm{~W}$ panels & 0 & 415 & 405 & 646 \\
\hline $\mathrm{N}^{\circ}$ solar panels rows & 0 & 29 & 29 & 29 \\
\hline $\mathrm{N}^{\circ}$ solar panels per row & 0 & 14 & 14 & 22 \\
\hline Daily expense for energy purchase without RES[€] & 582 & 581 & 581 & 581 \\
\hline Optimized daily expense for the energy purchase [€] & 569 & 455 & 445 & 489 \\
\hline Total optimized daily expense $[€]$ & 571 & 461 & 451 & 498 \\
\hline Daily revenues $[€]$ & 13 & 126 & 135 & 92 \\
\hline Monthly revenues $[€]$ & 393 & 3900 & 4200 & 2851 \\
\hline Daily O\&M costs of wind system [€] & 1 & 1 & 1 & 1 \\
\hline Daily O\&M costs of solar system [€] & 0 & 5 & 5 & 7 \\
\hline
\end{tabular}

Table 4. Optimization results of January, May, July and October

\subsection{Economic Analysis}

The results obtained for the 12 months are the input data for the economic analysis. The amortization assessment and the NPV evaluation is therefore performed (Section 3.5).

Taken into account the PV plant peak power and wind rated power (142 kW and $12 \mathrm{~kW}$ respectively), from the equations of paragraph 3.5 , the annual operating and maintenance costs result to be $3,217 €$; the total annual revenues are 28,418 $€$.

Table 5 shows the amounts of amortization, the Overall Installation Cost $\left(C_{i, t o t}\right)$ and the residual value at the end of the year $\left(V_{r}\right)$. When $V_{r}$ in Eq. (21) becomes negative, amortization is concluded.

$$
V_{r}=C_{i, t o t}-n * A
$$

Table 6 reports Values of Revenues, Amortization, $C_{i, t o t}$, operating and maintenance costs $\left(C_{O \& M}\right)$, Cash flows, Net Present Value (NPV) over 25 years. 


\begin{tabular}{|c|c|c|c|}
\hline Year & \multicolumn{1}{c}{$\begin{array}{c}\text { A } \\
{[\boldsymbol{\epsilon} / \text { year] }}\end{array}$} & $\begin{array}{c}\boldsymbol{C}_{\boldsymbol{i}, \text { tot }} \\
{[\boldsymbol{\epsilon}]}\end{array}$ & $\begin{array}{c}\boldsymbol{V}_{\boldsymbol{r}} \\
{[\boldsymbol{\epsilon}]}\end{array}$ \\
\hline 1 & 16803 & 186700 & 169897 \\
\hline 2 & 16803 & 186700 & 153094 \\
\hline 3 & 16803 & 186700 & 136291 \\
\hline 4 & 16803 & 186700 & 119488 \\
\hline 5 & 16803 & 186700 & 102685 \\
\hline 6 & 16803 & 186700 & 85882 \\
\hline 7 & 16803 & 186700 & 69079 \\
\hline 8 & 16803 & 186700 & 52276 \\
\hline 9 & 16803 & 186700 & 35473 \\
\hline 10 & 16803 & 186700 & 18670 \\
\hline 11 & 16803 & 186700 & 1867 \\
\hline
\end{tabular}

Table 5. Values of Amortization (A), $C_{i, t o t}$, and $V_{r}$.

\begin{tabular}{|c|c|c|c|c|c|c|}
\hline Year & $\begin{array}{c}\text { Revenues } \\
\text { [€/year] }\end{array}$ & $\begin{array}{c}C_{i, t o t} \\
{[€]}\end{array}$ & $\begin{array}{c}\text { A } \\
\text { [€/year] }\end{array}$ & $\begin{array}{c}C_{O \& M} \\
{[€ / \text { year] }}\end{array}$ & $\begin{array}{c}\text { Cash Flows } \\
\text { [€/year] }\end{array}$ & $\begin{array}{c}\text { NPV } \\
{[€]}\end{array}$ \\
\hline 0 & 0 & 186700 & 0 & 0 & -186700 & -186700 \\
\hline 1 & 28419 & 0 & 16803 & 3218 & 21590 & -165840 \\
\hline 2 & 28419 & 0 & 16803 & 3218 & 21590 & -145686 \\
\hline 3 & 28419 & 0 & 16803 & 3218 & 21590 & -126213 \\
\hline 4 & 28419 & 0 & 16803 & 3218 & 21590 & -107399 \\
\hline 5 & 28419 & 0 & 16803 & 3218 & 21590 & -89221 \\
\hline 6 & 28419 & 0 & 16803 & 3218 & 21590 & -71657 \\
\hline 7 & 28419 & 0 & 16803 & 3218 & 21590 & -54688 \\
\hline 8 & 28419 & 0 & 16803 & 3218 & 21590 & -38292 \\
\hline 9 & 28419 & 0 & 16803 & 3218 & 21590 & -22451 \\
\hline 10 & 28419 & 0 & 16803 & 3218 & 21590 & -7146 \\
\hline 11 & 28419 & 0 & 16803 & 3218 & 21590 & 7642 \\
\hline 12 & 28419 & 0 & 0 & 3218 & 14365 & 17148 \\
\hline 13 & 28419 & 0 & 0 & 3218 & 14365 & 26333 \\
\hline 14 & 28419 & 0 & 0 & 3218 & 14365 & 35207 \\
\hline 15 & 28419 & 0 & 0 & 3218 & 14365 & 43781 \\
\hline 16 & 28419 & 0 & 0 & 3218 & 14365 & 52065 \\
\hline 17 & 28419 & 0 & 0 & 3218 & 14365 & 60069 \\
\hline 18 & 28419 & 0 & 0 & 3218 & 14365 & 67803 \\
\hline 19 & 28419 & 0 & 0 & 3218 & 14365 & 75274 \\
\hline 20 & 28419 & 0 & 0 & 3218 & 14365 & 82493 \\
\hline 21 & 28419 & 0 & 0 & 3218 & 14365 & 89468 \\
\hline 22 & 28419 & 0 & 0 & 3218 & 14365 & 96208 \\
\hline 23 & 28419 & 0 & 0 & 3218 & 14365 & 102719 \\
\hline 24 & 28419 & 0 & 0 & 3218 & 14365 & 109010 \\
\hline 25 & 28419 & 0 & 0 & 3218 & 14365 & 115088 \\
\hline
\end{tabular}

Table 6. Values of Revenues, Amortization, $C_{i, t o t}, C_{O \& M}$, Cash flows, NPV over 25 years. 


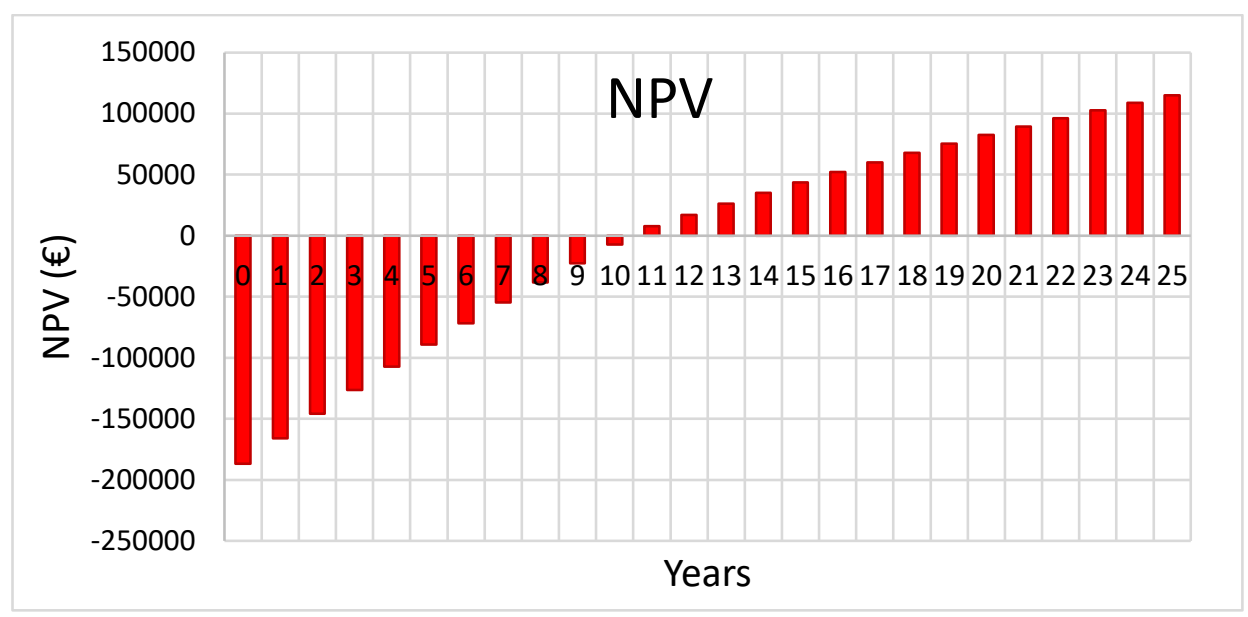

Figure 7. NPV profile over 25 years

Figure 7, derived from table 6, illustrates the NPV values for wind and PV plants in 25 years. As evident, after 11 years NPV reaches a positive value, and the investment return is obtained.

\section{Conclusions}

A procedure based on a MILP formulation has been proposed to reach the optimal sizing of both PV and wind energy plants, starting from the knowledge of the power required by the loads and the site geographical location. The monthly/ seasonality optimization of renewable generation has been performed in order to take into account not homogeneous seasonal energy consumption. The procedure was applied to a real industrial plant located in Rome area and the obtained results show the usefulness of the methodology to identify the optimal choice that combines the needs of the industrial plant with the RES availability and the achievable savings.

The procedure is suitable for any generic industrial site, including those not operating all year long. The integrated technical-economic procedure is useful to correctly define the investments according to the different Company's objectives.

\section{Acknowledgements}

The authors would like to thank ATAC S.p.a (The city of Rome Transportation Company) for the measurement campaign carried out on the industrial plant. 


\section{References}

[1] U. Grasselli, R. Lamedica, A. Ruvio, Management policies for residential and tertiary users: a measurement campaign, International Symposium on Power Electronics, Electric Drives, Automation and Motion 2014, 18-20 June 2014. DOI: $10.1109 /$ SPEEDAM.2014.6872118

[2] G. Graditi, M.G. Ippolito, R. Lamedica, A. Piccolo, A. Ruvio, E. Santini, P. Siano, Innovative control logics for a rational utilization of electric loads and air-conditioning systems in a residential building, Energy Build. 102 (2015) 1-17. DOI: https://doi.org/10.1016/i.enbuild.2015.05.027

[3] H. Dagdougui, R. Minciardi, A. Ouammi, M. Robba, R. Sacile, Modeling and optimization of a hybrid system for the energy supply of a “Green" bulding, Energy Conversion and Management 64 (2012) 351-363.

[4] R. Lamedica, E. Santini, S. Teodori, Electrical loads management in a smart building supplied by PV sources in power scenario, International Review of Electrical Engineering (I.R.E.E.), Vol. 9, No 5 (2014).

DOI: https://doi.org/10.15866/iree.v9i5.4216

[5] A.S.O. Ogunjuyigbe, T.R. Ayodele, O.A. Akinola, User satisfaction-induced demand side load management in residential buildings with user budget constraint, Applied Energy 187 (2017) 352-366. DOI https://doi.org/10.1016/i.apenergy.2016.11.071

[6] Vinko Lešic', Anita Martinc 'evic', Mario Vašak, Modular energy cost optimization for buildings with integrated microgrid, Applied Energy 197 (2017) 14-28. DOI: https://doi.org/10.1016/j.apenergy.2017.03.087

[7] Mengmeng Yu, Renzhi Lu, Seung Ho Hong, A real-time decision model for industrial load management in a smart grid, Applied Energy 183 (2016) 1488-1497. DOI: https://doi.org/10.1016/j.apenergy.2016.09.021

[8] Ministry of economic development, general directive for security for supply and energy infrastructure, the national energy situation in italy 2016.

[9] Lv T, Ai Q. Interactive energy management of networked microgrids-based active distribution system considering large-scale integration of renewable energy resources, Applied Energy 2016;163:408-22. DOI: https://doi.org/10.1016/i.apenergy.2015.10.179 
[10] Sahand Behboodi, David P. Chassin, Curran Crawford, Ned Djilali, Renewable resources portfolio optimization in the presence of demand response, Applied Energy $162 \quad$ (2016) $139-148 . \quad$ DOI: https://doi.org/10.1016/i.apenergy.2015.10.074

[11] Xiaonan Wang, Ahmet Palazoglu, Nael H. El-Farra, Operational optimization and demand response of hybrid renewable energy systems, Applied Energy 143 (2015) 324-335. DOI: https://doi.org/10.1016/j.apenergy.2015.01.004

[12] R. Morales, D. Sàez, L.G. Marìn, A. Nuñez, Microgrid planning based on fuzzy interval models of renewable sources, 2016 IEEE International Conference on Fuzzy Systems (FUZZ-IEEE), 24-29 July 2016. DOI: 10.1109/FUZZ$\underline{\text { IEEE.2016.7737706 }}$

[13] Vitor N. Coelho, Igor M. Coelho,, Bruno N. Coelho, Agnaldo J.R. Reis, Rasul Enayatifar, Marcone J.F. Souza, Frederico

G. Guimarães, A self-adaptive evolutionary fuzzy model for load forecasting problems on smart grid environment, Applied Energy 169 (2016) 567-584. DOI: https://doi.org/10.1016/i.apenergy.2016.02.045

[14] R. Atia, N. Yamada, Sizing and analysis of renewable energy and battery system in residential microgrid, IEEE Trans. Smart Grid, vol. 7, no. 3, May 2016.

[15] I. Sansa, R. Villafafila, N.M. Bellaaj, Optimal sizing design of an isolated microgrid using loss of power supply probability, $20156^{\text {th }}$ International Renewable Energy Congress (IREC), 24-26 March 2015.

[16] Cervone, A., Carbone, G., Santini, E., Teodori, S. “Optimization of the battery size for PV systems under regulatory rules using a Markov-Chains approach" Renewable Energy, Elsevier - Volume 85, January 2016, pages 657-665.

[17] M.E.G. Urias, E.N. Sanchez, L.J. Ricalde, Electrical microgrid optimization via a new recurrent neural network, IEEE Systems Journal, vol. 9, no. 3, Sept. 2015.

[18] Y. Hongxing, Z. Wei, L. Chengzhi, Optimal design and techno-economic analysis of a hybrid solar-wind power generation system, Applied energy 86 (2009) 163-169. DOI: https://doi.org/10.1016/i.apenergy.2008.03.008

[19] O. Ekren, B. Yetkin Ekren, Size optimization of a PV/wind hybrid energy conversion system with battery storage using response surface methodology, Applied Energy 85 (2008) 1086-1101.

[20] Anh-Tuan Nguyen, Sigrid Reiter, Philippe Rigo, A review on simulation-based optimization methods applied to building performance analysis, Applied Energy 113 (2014) 1043-1058. 
[21] Arnau González, Jordi-Roger Riba, Antoni Rius, Rita Puig, Optimal sizing of a hybrid grid-connected photovoltaic and wind power system, Applied Energy 154 (2015) 752-762.

[22] A.S. Eldessouky, H.A. Gabbar, Microgrid renewables dynamic and static performance optimization using genetic algorithm, 2015 IEEE International Conference on Smart Energy Grid Engineering (SEGE), 17-19 Aug. 2015.

[23] Y.A. Katsigiannis, P.S. Georgilakis, E.S. Karapidakis, Multiobjective genetic algorithm solution to the optimum economic and environmental performance problem of small autonomous hybrid power systems with renewables, IET Renew. Power Gener., 2010, vol. 4, Iss. 5, pp. 404-419. DOI: 10.1049/iet-rpg.2009.0076

[24] T. Khatib, A. Mohamed, K. Sopian, Optimization of a PV/wind micro-grid for rural housing electrification using a hybrid iterative/genetic algorithm: case study of Kuala Terengganu, Malaysia, Energy Build. 47 (2012) 321-331. DOI: https://doi.org/10.1016/i.enbuild.2011.12.006

[25] Y. Lu, S. Wang, Y. Zhao, C. Yan, Renewable energy system optimization of low/zero energy buildings using singleobjective and multi-objective optimization methods, Energy and Build. 89 (2015) 61-75.

[26] H. Yang, L. Lu, W. Zhou, A novel optimization sizing model for hybrid solar-wind power generation system, Solar Energy 81 (2007) 76-84.

[27] H.X. Yang, L. Lu, J. Burnett, Weather data and probability analysis of hybrid photovoltaic-wind power generation systems in Hong Kong, Renewable Energy 28 (2003) 1813-1824.

[28] D. Bienstock, Electrical Transmission System Cascades and Vulnerability: An Operations Research Viewpoint, SIAMMOS Series on Optimization (2015).

[29] K. Kasukana, H.J. Vermaak, B.P. Numbi, Optimal sizing of a hybrid energy plant using linear programming, IEEE PES PowerAfrica Conference and Exposition, Johannesburg, South Africa, 09-13 July 2012.

[30] T.M. Kneiske, M. Braun, D.I. Hidalgo-Rodriguez, A new combined control algorithm for PV-CHP hybrid systems, Applied Energy xxx (2017) xxx-xxx In press https://doi.org/10.1016/j.apenergy.2017.06.047.

[31] Wolsey, Laurence A. Integer programming. Vol. 42. New York: Wiley, 1998.

[32] Jünger, Michael, et al., eds. 50 years of integer programming 1958-2008: From the early years to the state-of-theart. Springer Science \& Business Media, 2009.

[33] ISO IEC 61400.

[34] http://www.societaelettricaitaliana.it/documents/MINIEOLICO_SEI-MD_5KW.pdf 
[35] James F. Manwell, Jon G. McGowan, Anthony L. Rogers Wind Energy Explained: Theory, Design and Application Editore: John Wiley and Sons Ltd Anno: 2009

[36] J.V. Segyro, T.W. Lambert, Modern estimation of the parameters of the Weibull wind speed distribution for wind energy analysis, Journal of Wind Engineering and Industrial Aerodynamics 85 (2000) 75-84.

[37] The Italian UNI 10349: Heating and cooling of buildings, Climate Data: methods to divide the hourly solar irradiance into the direct and diffuse fraction and to calculate the radiant energy received from a fixed surface, however inclined and oriented;

[38] ENEA - National Agency for New Technologies, Energy and Sustainable Economic Development data bank solar radiation: http://www.solaritaly.enea.it/CalcComune/Calcola.php.

[39] E. Karatepe, M. Boztepe, M. Colak, Development of a suitable model for characterizing photovoltaic arrays with shaded solar cells, Solar Energy 81 (2007) 977-992.

[40] A. Cervone, E. Santini, S. Teodori, D. Zaccagnini, “Impact of regulatory rules on economic performance of PV power plants", Renewable Energy, Elsevier - Volume 74, 201, pages 78-86.

[41] Capasso, R. Lamedica, L. Podestà, A. Ruvio, S. Sangiovanni, G. C. Lazaroiu and G. A. Maranzano. “A measurement campaign in a metro-train deposit/maintenance and repair site for PV production optimal sizing" IEEE EEEIC 2015 - 15th Conference on Environment and Electrical Engineering.

[42] NREL - National Renewable Energy Laboratory: https://www.nrel.gov/analysis/tech-lcoe-re-cost-est.html 